\title{
PERFIL MICROBIOLÓGICO DE PEIXES E ÁGUA DE CULTIVO EM PESQUE-PAGUES SITUADOS NA REGIÃO NORDESTE DO ESTADO DE SÃO PAULO
}

\section{C.S. Lorenzon, P. Gatti Junior, A.P. Nunes, F.R. Pinto, C. Scholten, S.N. Honda, L.A. do Amaral}

Universidade Estadual Paulista, Faculdade de Ciências Agrárias e Veterinárias, Departamento Medicina Veterinária Preventiva e Reprodução Animal, Via de Acesso Prof. Paulo Donato Castellane, s/no, CEP 14884-900, Jaboticabal, SP, Brasil. E-mail: cintia.lorenzon@gmail.com

\section{RESUMO}

O objetivo deste trabalho foi determinar o número de coliformes totais, termotolerantes, Staphylococcus coagulase positivo e a presença de bactéria do gênero Salmonella no músculo, no tecido superficial, no trato gastrintestinal de peixes e na água de cultivo de pesque-pagues situados na microbacia do Córrego Rico, SP. Não foi detectado Staphylococcus coagulase positivo em nenhuma amostra de água e peixe. O número mais provável (NMP) de coliformes totais no peixe variou de $2,0 \times 10$ a >1,1 x $10^{4}$ NMP.100 $\mathrm{mL}^{-1}$, na água de cultivo variou de 4,2 x $10^{4}$ a $>2,4 \times 10^{5} \mathrm{NMP} .100 \mathrm{~mL}^{-1}$. A contagem de coliformes termotolerantes no peixe variou de $<3$ a 5,1 x $10^{3} \mathrm{NMP} \cdot \mathrm{g}^{-1}$, na água de cultivo variou de $3,8 \times 10^{2}$ a 2,0 $\times 10^{4} \mathrm{NMP} .100 \mathrm{~mL}^{-1}$. Não houve diferença estatística $(\mathrm{P}>0,05)$ entre as populações de micro-organismos pesquisados na água, pele e trato gastrintestinal, o que reflete uma relação entre a presença dos micro-organismos na água e nesses dois locais analisados. Foi isolada Salmonella sp. em uma amostra de músculo e em duas amostras de trato gastrintestinal. $\mathrm{O}$ pescado pode ser veículo de contaminação cruzada, tendo como fonte dos micro-organismos a pele e o trato gastrintestinal para sua própria musculatura. Portanto, o monitoramento da qualidade da água é de suma importância para garantir a produção de peixes com boa qualidade.

PALAVRAS-CHAVE: Pesque-pague, coliformes totais e termotolerantes, Salmonella, Staphylococcus
coagulase positivo.

ABSTRACT

MICROBIOLOGICAL PROFILE OF FISH AND POND WATER IN FEE-FISHING LOCATED IN THE NORTHEAST REGION OF SÃO PAULO STATE, BRAZIL. The objective of this study was to determine the number of total and thermotolerant coliforms, coagulase-positive Staphylococcus, and the presence of bacteria of the genus Salmonella in the muscle, surface tissue, and gastrointestinal tract of fish, and in the pond water of fee-fishing establishments located in the Córrego Rico microwatershed in the state of São Paulo, Brazil. Coagulase-positive Staphylococcus was not detected in any sample of pond water or fish. The most probable number (MPN) of total coliforms in fish ranged from $2.0 \mathrm{x}$ 10 to $>1.1 \times 10^{4} \mathrm{NMP} .100 \mathrm{~mL}^{-1}$, while in pond water it ranged from $4.2 \times 10^{4}$ to $>2.4 \times 105 \mathrm{NMP} .100$ $\mathrm{mL}^{-1}$. The count of thermotolerant coliforms in fish ranged from $<3$ to $5.1 \times 10^{3} \mathrm{NMP} . \mathrm{g}^{-1}$, while in pond water it ranged from $3.8 \times 10^{2}$ to $2.0 \times 10^{4} \mathrm{NMP} .100 \mathrm{~mL}^{-1}$. There was no statistical difference $(\mathrm{P}>0.05)$ among the studied populations of microorganisms in pond water, surface tissue and gastrointestinal tract, which reflects a relationship between the presence of microorganisms in the water and in the two tissues analyzed. Salmonella sp. was isolated in one sample of muscle and in two samples of gastrointestinal tract. The fish can be a vehicle for cross contamination, having the gastrointestinal tract and the surface tissue as a source of microorganisms for its muscles. Therefore, monitoring the water quality is important to ensure the production of fish with good quality.

KEY WORDS: Fee-fishing, total and thermotolerant coliforms, Salmonella, coagulase-positive Staphylococcus.

\section{INTRODUÇÃO}

O Brasil possui condições hidrográficas e climáticas favoráveis para o desenvolvimento da piscicultura. No Estado de São Paulo, ocorreu um aumento expressivo no número de propriedades que se dedicam a essa atividade. Além de polos de produção, tornaram-se também áreas de lazer para a população, já que muitos deles promovem a atividade da pesca. São os chamados "pesquepagues", muito difundidos na região (CASTAGNOLLI, 1995). 
O sucesso econômico dessa atividade recreativa depende de boa manutenção da qualidade da água. No entanto, em muitas situações, estes estabelecimentos não têm o aporte tecnológico adequado e vêm gerando diversos problemas, notadamente ambientais e até mesmo de saúde pública.

A qualidade microbiológica da água dos viveiros pode influenciar na qualidade microbiológica do peixee de seus produtos (PAL;DASGUPTA, 1992). Esses alimentos têm sido associados a doenças humanas e são veículo de transmissão de micro-organismos patogênicos e intoxicações, constituindo-se em problema de saúde pública.

Os coliformes apontam a possibilidade da presença de poluição fecal, ou seja, ocasionada por organismos que ocorrem em grande número na microbiota intestinal humana ou de animais homeotérmicos (PÁduA, 2003).

Os coliformes não são habitantes normais da microbiota intestinal dos peixes, no entanto, têm sido isolados do trato gastrintestinal desses animais. Esse fato indica que a microbiota bacteriana do peixe pode revelar as condições microbiológicas da água onde o peixe se encontra. (AL-HARBI, 2003; GUZMÁN et al., 2004).

Em alimentos crus, a presença de Staphylococcus aureus é comum e pode não estar relacionada com contaminação humana, as enterotoxinas produzidas por S. aureus são outra causa séria de intoxicações após o consumo de peixe e seus produtos e representam um risco para a saúde pública (GERMANO et al., 1993).

Registros epidemiológicos em todo o mundo mostram a importância da Salmonella spp. como a maior causadora de doenças bacterianas de origem alimentar no ser humano, o qual se infecta mediante a ingestão de alimentos contaminados.

A presença de diversas bactérias entéricas, tais como coliformes termotolerantes, Salmonella e Staphylococcus, nos tanques de aquicultura sugerem a necessidade de um controle rígido de higiene durante o manejo e a evisceração do peixe, a fim de prevenir a transferência de bactérias da água ou do trato gastrintestinal dos animais para a musculatura dos peixes.

Pouco se conhece a respeito do tipo de manejo realizado em muitos pesque-pagues e suas consequências sobre a qualidade da água e sanidade dos peixes pescados e destinados ao consumo. Estes problemas indicam a necessidade de estudos que possam assegurar a sustentabilidade desta atividade.

Diante desta situação o presente trabalho teve como objetivo determinar o número de coliformes totais, termotolerantes, Staphylococcus coagulase positivo e a presença de bactéria do gênero Salmonella no músculo, notecido superficial, no trato gastrintestinal de peixes e na água de cultivo de pesque-pagues situados na microbacia do Córrego Rico, região nordeste do Estado de São Paulo.

\section{MATERIAIS E MÉTODOS}

\section{Local, colheita e transporte das amostras de água e de peixe}

As amostras de água do viveiro e os peixes foram colhidos entre abril e junho de 2008, no período da manhã, durante a semana, sendo utilizados para este fim cinco pesque-pagues situados na microbacia do Córrego Rico, região nordeste do Estado de São Paulo. As amostras de água do viveiro foram colhidas em cinco pontos distintos (total de amostras de água foi de 25), em frascos estéreis para as análises microbiológicas.

Foram colhidosaleatoriamente dezexemplares de peixes adultosnotanquecomo auxílio detarrafase/ou varas de pescas (total de amostras de peixe foi de 50). Em seguida os peixes capturadosforam colocados em sacos plásticos esterilizadoseemimersãoem gelo para serem sacrificados e analisadas as diferentes partes.

As amostras foram transportadas em caixa isotérmicas com gelo reciclável para o Laboratório de Microbiologia localizado no Departamento de Engenharia Rural da Faculdade de Ciências Agrárias e Veterinárias de Jaboticabal (UNESP-FCAV).

\section{Preparação das amostras}

\section{Água de enxaguadura da pele (APHA, 2001)}

Foram adicionados $200 \mathrm{~mL}$ de água peptonada 0,1\% esterilizada no saco plástico contendo o peixe. Em seguida, o peixe foi massageado durante um minuto para transferir os micro-organismos da pele para a água peptonada. Desta maneira, foi obtida uma amostra da água de enxaguadura que foi utilizada nas análises microbiológicas.

\section{Tecido muscular (APHA, 2001)}

Antes de serem dissecados, a pele dos peixes foi lavada com álcool $70 \%$ para evitar contaminação do seu interior. Em seguida, os peixes foram dissecados como auxílio deinstrumentos esterilizados, tomandosedevidocuidado para quenãoocorresserompimento do trato gastrintestinal. Foram utilizados $25 \mathrm{~g}$ de músculo de cada peixe, que foram pesados em placas de Petri estéreis, procedendo-se então a diluição do músculo com a adição de $225 \mathrm{~mL}$ de água peptonada tamponada a $0,1 \%$ que foi homogeneizado por um minuto, obtendo-se assim a diluição $10^{-1}$.

\section{Trato gastrintestinal (APHA, 2001)}

Todo o conteúdo do trato gastrintestinal do peixe foi retirado e pesado. Foi adicionada a quantidade de 
água peptonada $0,1 \%$ em volume proporcional para obtenção da diluição $10^{-1}$. Novas diluições decimais foram realizadas transferindo-se $1 \mathrm{~mL}$ da diluição anterior para tubos contendo $9 \mathrm{~mL}$ do diluente até obter-se a diluição $10^{-4}$.

Determinação do número mais provável (NMP) de coliformes totais e termotolerantes na água e no peixe (AРHA, 1998)

Foi utilizada a técnica dos tubos múltiplos (série de 5 tubos para a água do viveiro e série de 3 tubos para o peixe). A avaliação dos coliformes totais e termotolerantes foram baseadas nas recomendações do APHA (1998).

\section{Contagem de Staphylococcus coagulase positivos (APHA, 1998).}

Volumes de $100 \mathrm{~mL}$ das amostras de água e suas diluições decimais foram filtrados em membrana com porosidade de $0,45 \mu$ m e transferidos para placas de Petri contendo Ágar Baird Parker (HIMEDIA). Para as diferentes partes do peixe, foi transferido $0,1 \mathrm{~mL}$ das diluições obtidas das amostras da água de enxaguadura da pele, do músculo e trato gastrintestinal para placas de Petri, contendo Ágar Baird Parker. O inóculo foi espalhado com auxílio da alça de Drigalsky. As placas de Baird Parker foram incubadas a $36^{\circ} \mathrm{C}$ por 48 horas.

As colônias características do gênero Staphylococcus foram quantificadas, o cálculo para estimativa de UFC. $\mathrm{g}^{-1}$ ou UFC. $\mathrm{mL}^{-1}$ foi feito multiplicando onúmero de colônias pela diluição da amostra. Em seguida, foram coradas pelo método de Gram e submetidas ao teste da catalase e coagulase (MAC FADDIN, 1976).

Pesquisa da presença de bactérias do gênero Salmonella (APHA, 2001).

Foi feito um pré-enriquecimento primário, diluindo $450 \mathrm{~mL}$ da amostra de água em $50 \mathrm{~mL}$ de água peptonada tamponada $1 \%$, ea incubação foi realizada a $37^{\circ} \mathrm{C}$ por 24 horas. As amostras do músculo, do trato gastrintestinal e da água de exaguadura dos peixes obtidas em água peptonada a 0,1\% foram incubadas em estufa a $37^{\circ} \mathrm{C}$ por 24 horas.

No enriquecimento seletivo foi inoculado $1 \mathrm{~mL}$ de cada cultura do pré-enriquecimento em $10 \mathrm{~mL}$ de caldo selenito cistina eem $10 \mathrm{~mL}$ de caldo RappaportVassiliadis, adicionados de $0,1 \mathrm{~mL}$ de uma solução de novobiocina a $0,4 \%$. A incubação foi realizada a $37^{\circ} \mathrm{C}$ por 24 horas. A partir da cultura em caldo de enriquecimento, foi retirada uma alíquota de cada e inoculada emágar verde brilhante eágar MacConkey (plaquemaento seletivo), seguido de incubação a $37^{\circ} \mathrm{C}$ por 24 horas.
A identificação presuntiva foi realizada inoculando as colônias com características sugestivas do gênero Salmonella em tubos contendo ágar TSI inclinado ("Triple Sugar Iron") que foi incubado a $37^{\circ} \mathrm{C}$ por 24 horas. As colônias que se presumiram ser de Salmonella foram submetidas ao teste de aglutinação com soro antissalmonela polivalente somático $\mathrm{O}$ e soro antissalmonela polivalente flagelar $\mathrm{H}$.

\section{Análise estatistica}

Os resultados microbiológicos foram analisados utilizando-se valores em logaritmo e as médias comparadas pelo teste de Tukey, a $5 \%$ de probabilidade (SAS, 1991).

Foram feitas comparações de médias de coliformes (totais e termotolerantes) e Staphylococcus coagulase entre os tecidos nos peixes e na água de cultivo dentro de cada pesque-pague.

\section{RESULTADOS E DISCUSSÃO}

Os resultados dos números mais prováveis(NMP) de coliformes totais, termotolerantes e contagem de Staphylococcus sp. nas diferentes partes do peixe e na água de cultivo dos cinco pesque-pagues analisados estão apresentado na Tabela 1.

Não foi detectado Staphylococcus coagulase positivo em nenhuma amostra de peixe e de água. Para a contagem de Staphylococcus sp. não houve diferença significativa entre as diferentes partes do peixe e na água de cultivo ( $P>0,05)$, com exceção do pesque-pague 1 (Tabela 1), onde a contagem de Staphylococcus sp. na água do viveiro difere significativamente quando comparado com aquelas encontradas nas amostras de peixe $(\mathrm{P}<0,05)$. Na contagem de Staphylococcus sp. a água de enxaguadura da pele apresentou médias que variam de $1,0 \times 10^{2}$ a $3,3 \times 10^{5}$ UFC. $\mathrm{mL}^{-1}$; no músculo de $1,0 \times$ $10^{2}$ a $6,7 \times 10^{3}$ UFC. $^{-1}$; no trato gastrintestinal de 1,0 $\times 10^{3}$ a $2,9 \times 10^{5}$ UFC. $\mathrm{g}^{-1}$; e na água do viveiro de < 20 a $3,3 \times 10^{2}$ UFC. $\mathrm{mL}^{-1}$.

Em Zâmbia (África), tanques de pisciculturas apresentaram contagens de Staphylococcus spp. na ordem de $10^{6}$ UFC.mL ${ }^{-1}$ (NTENGWE; EDEMA, 2008), ou seja, maiores que os encontrados neste trabalho.

A ausência de Staphylococcus coagulase positivo pode ser explicada pelo fato de que essas bactérias geralmente são encontradas no corpo humano (trato respiratório, mucosas nasais e pele) e transferida ao alimento por pessoas com precários hábitos de higiene durante o manuseio e/ou armazenamento do produto. No presente estudo, os peixes foram coletados diretamente dos viveiros, ou seja, não receberam nenhum tipo de manipulação. 
Tabela 1 - Média dos resultados dos números mais prováveis (NMP) de coliformes totais (CT), termotolerantes (CTer) e contagem de Staphylococcus sp. nas diferentes partes do peixe e na água do viveiro dos pesque-pagues localizados na região nordeste do Estado de São Paulo, no período de abril a junho de 2008.

\begin{tabular}{|c|c|c|c|c|}
\hline $\begin{array}{l}\text { Pesque- } \\
\text { pague }\end{array}$ & Amostras & CT (NMP.100mL-1 ou g $\mathrm{g}^{-1}$ ) & CTer (NMP.100mL-1 ou g ${ }^{-1}$ ) & $\begin{array}{c}\text { Staphylococcus sp. (UFC. } \\
\mathrm{mL}^{-1} \mathrm{ou} \mathrm{g}^{-1} \text { ) }\end{array}$ \\
\hline \multirow{4}{*}{1} & Pele & $1,5 \times 10^{3} \mathrm{~b}^{*}$ & $1,2 \times 10^{3} \mathrm{ab}$ & $3,3 \times 10^{5} \mathrm{a}$ \\
\hline & Músculo & $2,0 \times 10 \mathrm{c}$ & $0,6 \times 10 \mathrm{~b}$ & $6,7 \times 10^{3} \mathrm{a}$ \\
\hline & Trato gastrintestinal & $5,8 \times 10^{3} \mathrm{~b}$ & $5,1 \times 10^{3} \mathrm{a}$ & $2,9 \times 10^{5} \mathrm{a}$ \\
\hline & Água do viveiro & $4,2 \times 10^{4} \mathrm{a}$ & $0,8 \times 10^{3} \mathrm{a}$ & $2,0 \times 10 \mathrm{~b}$ \\
\hline \multirow{4}{*}{2} & Pele & $1,8 \times 10^{3} \mathrm{~b}^{*}$ & $<3,0 \times 10 b$ & $1,0 \times 10^{4} \mathrm{a}$ \\
\hline & Músculo & $4,9 \times 10 \mathrm{c}$ & $<0,3 \times 10 b$ & $5,5 \times 10^{2} \mathrm{a}$ \\
\hline & Trato gastrintestinal & $2,6 \times 10^{3} \mathrm{~b}$ & $2,9 \times 10^{3} \mathrm{a}$ & $2,5 \times 10^{4} \mathrm{a}$ \\
\hline & Água do viveiro & $5,3 \times 10^{4} \mathrm{a}$ & $4,4 \times 10^{2} \mathrm{a}$ & $<2,0 \times 10$ \\
\hline \multirow{4}{*}{3} & Pele & $3,1 \times 10^{3} \mathrm{~b}^{*}$ & $9,5 \times 10^{2} \mathrm{a}$ & $2,2 \times 10^{4} a$ \\
\hline & Músculo & $2,4 \times 10 \mathrm{c}$ & $0,7 \mathrm{~b}$ & $1,0 \times 10^{2} \mathrm{a}$ \\
\hline & Trato gastrintestinal & $5,0 \times 10^{3} \mathrm{ab}$ & $2,1 \times 10^{3} \mathrm{a}$ & $2,0 \times 10^{3} \mathrm{a}$ \\
\hline & Água do viveiro & $5,1 \times 10^{4} a$ & $3,8 \times 10^{2} \mathrm{a}$ & $<2,0 \times 10$ \\
\hline \multirow{4}{*}{4} & Pele & $>1,1 \times 10^{4}$ & $1,4 \times 10^{3} \mathrm{a}^{*}$ & $1,0 \times 10^{2} \mathrm{a}$ \\
\hline & Músculo & $>1,1 \times 10^{3}$ & $0,6 \times 10 b$ & $3,7 \times 10^{2} \mathrm{a}$ \\
\hline & Trato gastrintestinal & $>1,1 \times 10^{4}$ & $1,2 \times 10^{3} \mathrm{a}$ & $1,0 \times 10^{3} \mathrm{a}$ \\
\hline & Água do viveiro & $>2,4 \times 10^{5}$ & $2,0 \times 10^{4} \mathrm{a}$ & $3,3 \times 10^{2} \mathrm{a}$ \\
\hline \multirow{4}{*}{5} & Pele & $>1,1 \times 10^{4}$ & $3,6 \times 10 b^{*}$ & $3,3 \times 10^{3} \mathrm{a}$ \\
\hline & Músculo & $>1,1 \times 10^{3}$ & $0,1 \times 10 \mathrm{c}$ & $1,0 \times 10^{2} \mathrm{a}$ \\
\hline & Trato gastrintestinal & $>1,1 \times 10^{4}$ & $2,5 \times 10^{3} \mathrm{a}$ & $3,4 \times 10^{4} \mathrm{a}$ \\
\hline & Água do viveiro & $>2,4 \times 10^{5}$ & $2,5 \times 10^{3} \mathrm{a}$ & $<2,0 \times 10$ \\
\hline
\end{tabular}

${ }^{*}$ Médias seguidas da mesma letra, em cada coluna e dentro do mesmo pesque-pague, não diferem estatisticamente, no nível de 5\% de probabilidade pelo Teste de Tukey.

Resultados semelhantes foram obtidos por CosTA et al. (2007) ao analisar amostras de sushi de salmão comercializados na Cidade de Sobral, CE. Também não detectaram Staphylococcus coagulase positivo, sendo que a contagem de Staphylococcus spp. variou de $<10^{2}$ a 3,0 x $10^{2}$ UFC. $^{-1}$.

Porém, pesquisas indicam que Staphylococcus coagulase negativo pode produzir enterotoxinas, contribuindo para a intoxicação alimentar. A esse respeito CunHA et al. (2006) verificaram a capacidade toxigênica de linhagens de Staphylococcus coagulase negativo e identificaram por PCR ("Polymerase Chain Reaction") os genes responsáveis pela produção de enterotoxinas. Dentre os alimentos analisados $22,7 \%$ foram positivos para Staphylococcus coagulase negativo com crescimento entre $10^{2}$ a $10^{6}$ UFC. $\mathrm{g}^{-1}$. Vale ressaltar que esses alimentos foram processados, portanto, ficaram sujeitos à contaminação pelos manipuladores.

Em Taiwan, S. epidermidis foi responsável pela morte de várias tilápias (Oreochromis spp.) entre1992 e 1996. Este foi o primeiro relato sobre o isolamento de estafilococos patogênico em tilápias (Huang et al., 1999). Nos pesque-pagues, várias pessoas ficam em contato direto com os peixes. Isto se torna um fator de risco tanto para o peixe como para o ser humano, uma vez que o S. epidermidis é responsável por 50 a $80 \%$ das infecções causadas por estafilococos coagulase negativo (LANCELLOTTI, 2006).
Noscinco pesque-pagues, o número mais provável (NMP) decoliformestermotolerantesnaágua decultivo e no trato gastrintestinal não apresentou diferenças significativas entre si $(\mathrm{P}>0,05)$. Nos pesque-pagues 1 e 2 (Tabela 1) o NMP dessas bactérias não difere estatisticamente $(\mathrm{P}>0,05)$ na pele e no músculo.

Nos pesque-pagues o NMP de coliformes totais na pele variou de $1,5 \times 10^{3}$ a $>1,1 \times 10^{4} \mathrm{NMP} .100 \mathrm{~mL}^{-1}$; no músculo variou de 2,0 × 10 a $>1,1 \times 10^{3} \mathrm{NMP} \cdot \mathrm{g}^{-1}$; no trato gastrintestinal variou de $2,6 \times 10^{3}$ a $>1,1 \times$ $10^{4} \mathrm{NMP} . \mathrm{g}^{-1}$; e na água de cultivo variou de $4,2 \times 10^{4}$ a $>2,4 \times 10^{5} \mathrm{NMP} .100 \mathrm{~mL}^{-1}$.

A grande concentração de coliformes totais na água dos pesque-pagues não representa necessariamente problemas para a saúde, uma vez que não é um indicativo de contaminação fecal. Porém, de acordo com EL-SHAfAr et al. (2004), a composição microbiológica da água de cultivo reflete a variedade de bactérias presentes na pele do peixe.

No presente estudo, a pele e o trato gastrintestinal dos peixes apresentaram contagens de coliformes totais semelhantes entre si, enquanto que no músculo a concentração permaneceu baixa, com exceção dos pesque-pagues 4 e 5 . A sua presença nas diferentes partes do peixe não indica diretamente a presença de patógenos, no entanto, serve como indicativo da qualidade higiênica e informa sobre o grau de poluição microbiana a que está exposto o alimento em estudo (Liuson, 2003). 
MARTINS et al. (2002) verificaram uma variação de 40 até $2,3 \times 10^{4}$ UFC. $g^{-1}$ de coliformes totais em filés de carpas (Cyprinus carpio) e tilápias (Oreochromis niloticus) evisceradas provenientes de pesque-pagues em Toledo, PR.

LiUSON (2003) analisou tilápias (Oreochromis spp.) inteiras oriundas de pesqueiros da região metropolitana deSão Paulo, SP, os resultados obtidos apresentaram uma variação de $<0,3$ até $4,6 \times 10^{7} \mathrm{NMP} \mathrm{g}^{-1}$ de coliformes totais, bem superiores comparados com o que foi encontrado no presente trabalho.

Para coliformes termotolerantes a água de enxaguadura da pele variou de $<3,0 \times 10$ a $1,4 \times 10^{3}$ NMP. $100 \mathrm{~mL}^{-1}$; no músculo variou de $<3$ a $6 \mathrm{NMP}^{-1}{ }^{-1}$; no trato gastrintestinal variou de $1,2 \times 10^{3}$ a $5,1 \times 10^{3}$ NMP.g ${ }^{-1}$; e na água de cultivo variou de $3,8 \times 10^{2}$ a $2,0 \times 10^{4}$ NMP.100 $\mathrm{mL}^{-1}$.

De acordo com o CONAMA 357/05 (CONSELHO..., 2005), para águas destinadas à aquicultura e à atividade de pesca (classe 2), a concentração de coliformes termotolerantes não deverá exceder $10^{3}$ NMP.100 $\mathrm{mL}^{-1} \mathrm{em} 80 \%$ ou mais de pelo menos 6 amostras coletadas durante o período de um ano. Como realizamos apenas uma coleta no ano não é possível concluir qual pesque-pague está em descordo com a legislação vigente.

Porém, três pesque-pagues (pesque-pague 1, 4 e 5) apresentaram valores superiores a $10^{3}$ NMP. 100 $\mathrm{mL}^{-1}$ de coliformes termotolerantes. Segundo Bord; TANNER (1998), a contaminação dos viveiros por coliformes termotolerantes pode ocorrer pelo aporte de fezes humanas e de animais homeotérmicos.

Durante o experimento foi possível observar vários animais, tais como caprinos, bovinos, cães e aves circulando no entorno dos viveiros. Outra possível via de contaminação por coliformes termotolerantes éa água de abastecimento. Fato observado por GATTI JUNIOR (2008) que encontrou variação de 2,19 a 4,14 log NMP.100 $\mathrm{mL}^{-1}$ de Escherichia coli na água de abastecimento dos viveiros dos pesque-pagues.

Como a qualidade microbiológica da água dos viveiros influencia na qualidade microbiológica do peixe (PAL; DASGUPTA, 1992), pode-se observar que a concentração de coliformes termotolerantes na água foi similar ao encontrado no trato gastrintestinal dos peixes.

Resultados similares encontrados neste experimento foram obtidos por AL-HARBI (2003) que, ao estudar tilápias híbridas (Oreochromis niloticus X Oreochromis aureus), verificou que coliformes termotolerantes na água e no trato gastrintestinal do peixe, que variaram de $2,87 \times 10^{2} \mathrm{a} \geq 1,6 \times 10^{3} \mathrm{NMP} .100 \mathrm{~mL}^{-1}$ e $2,37 \times 10^{2}$ a $\geq 1,1 \times 10^{3} \mathrm{NMP} \cdot \mathrm{g}^{-1}$, respectivamente, estavam correlacionados.

No presente estudo as altas concentrações de coliformes termotolerantes na água dos viveiros foram precedidas pelos altos números de colifor- mes no trato gastrintestinal e na pele dos peixes. Ordenando os níveis de contaminação de coliformes termotolerantes nos diferentes órgãos dos peixes em ordem decrescente temos: trato gastrintestinal $>$ pele $>$ músculo.

Resultados semelhantes foram obtidos por ELSHAFAiet al. (2004) na qual tilápias criadas em diferentes viveiros contaminados com efluentes obtiveram uma contaminação dessa bactéria ordenada em trato gastrintestinal $>$ brânquias $>$ pele $>$ fígado, enquanto no músculo não foi detectado coliforme termotolerante. Neste experimento o NMP de coliformes termotolerantes na água do viveiro variou de 1,7 $\mathrm{x}$ $10^{2}$ a $9,4 \times 10^{3}$ UFC. $100 \mathrm{~mL}^{-1}$, o trato gastrintestinal variou de $5,3 \times 10^{3}$ a $3,8 \times 10^{4} \mathrm{UFC}^{-g^{-1}}$ e a pele variou de $6,0 \times 10^{2}$ a $6,5 \times 10^{3}$ UFC.cm ${ }^{-1}$.

Com relação ao músculo analisado, todos apresentaram contagem de coliformes termotolerantes abaixo de $10^{2}$ NMP.g- .

LiRA et al. (2001), ao estudar peixe-serra (Pristis pectinata) comercializado em Maceió, AL, encon-

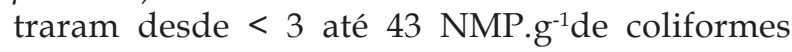
termotolerantes. RALL et al. (2008), ao analisarem peixe fresco comercializado na Cidade de Botucatu, SP, verificaram variações de $<3$ a $93 \mathrm{NMP} \cdot \mathrm{g}^{-1}$ de coliformes termotolerantes. TAVAREs et al. (2008) observaram uma variação de $<3$ a 3,6 NMP.g-1 de coliformes termotolerantes em tilápias cultivadas em sistemas de reúso de efluentes domésticos. Todos os resultados citados, anteriormente, corroboram com os achados do presente trabalho.

$\mathrm{O}$ risco envolvido no consumo de peixe contaminado não é necessariamente associado apenas à presença de bactérias no tecido utilizado para alimentação humana. A infecção humana pode ocorrer quando a parte comestível é contaminada durante o manuseio do pescado, veiculando micro-organismos para musculatura do peixe, equipamentos, outros alimentos, ambiente de preparo por micro-organismos presentes em outras partes do peixe (contaminação cruzada), geralmente vísceras, pele e brânquias (EsPOSTO et al., 2007). Esses autores advertiram para o cuidado na manipulação no momento da retirada das vísceras e no preparo do produto, pois esta é uma via potencial de transmissão de bactérias patogênicas.

Em pesque-pagues, MARTINs et al. (2002) verificaram que $67 \%$ e $50 \%$ das amostras dos filés de tilápia e de carpa, respectivamente, estavam acima de $10^{2}$ NMP. $\mathrm{g}^{-1}$ de coliformes termotolerantes. Os autores acreditam que estes valores excessivos podem ter ocorrido devido a uma manipulação inadequada do filetador/eviscerador, permitindo o contato do músculo com as vísceras.

VIEIRA et al. (2000) estudaram a influência das condições higiênico-sanitárias do processo de produção de filés de tilápias em Campina Grande, $\mathrm{PB}$. Os resultados mostraram contaminação crescente de 
coliformes totais e termotolerantes ao longo da cadeia produtiva. Peixes coletados no açude apresentaram 3 NMP.g $\mathrm{g}^{-1}$ de coliformes totais e termotolerantes, enquanto que no filé congelado coletado no frigorífico encontraram valores de $4,6 \times 10^{3} \mathrm{NMP} \cdot \mathrm{g}^{-1}$. Os autores concluíram que houve deficiências higiênicas por parte dos manipuladores e que o local de processamento dos peixes eram inadequado.

No pesque-pague 2, ocorreu presença de Salmonella sp. em $25 \mathrm{~g}$ de músculo em um peixe e também foi isolada em uma amostra de trato gastrintestinal. No pesque-pague 5, houve presença de Salmonella sp. em apenas uma amostra de trato gastrintestinal.

A presença de Salmonella sp. na musculatura do peixe encontrada no presente estudo está em desacordo com o parâmetro preconizado pela $\mathrm{RDC} \mathrm{n}^{\circ} 12$ (AGÊNCIA..., 2001), que prevê ausência desse agente em $25 \mathrm{~g}$ de pescado in natura. Sabe-se que, em alguns casos, são necessárias poucas células infectantes de Salmonella (1-10 células para alguns sorotipos) para causar sintomas clínicos no ser humano (LINDER, 2002; MARTINS, 2006).

Segundo EKPERIGIN; NAGAJARA (1998), vários sorovars de Salmonella são potencialmente patogênicos para o ser humano, podendo causar desde leves sintomas, como também levar o indivíduo até a morte. A cocção do alimento elimina o risco deste patógeno, porém, a maior preocupação é quando este é consumido cru, como nos casos de "sushi" e "sashimi" (MARTINS, 2006).

VIEIRA et al. (2000) verificaram que Salmonella spp. esteve presente ao longo da cadeia de produção de filés de tilápias. Foi isolada desde o peixe capturado no açude até no filé congelado coletado no posto de venda.

A presença de Salmonella sp. em duas amostras do trato gastrintestinal $(4,44 \%)$ é preocupante, pois essa bactéria pode contaminar o músculo durante sua manipulação. Como a maioria dos frequentadores dos pesque-pagues leva para casa o peixe eviscerado pelos funcionários, MARTINS et al. (2002) advertiram para a má manipulação e o baixo nível de processamento dos pescados nesses estabelecimentos.

No Egito, Youssef et al. (1992) verificaram a presença de Salmonella em tilápias em 3,9\% das amostras de trato gastrintestinal. Em Botucatu, SP, LINDER (2002) analisou o conteúdo intestinal de peixes provenientes de pesqueiros e obteve presença desse patógeno em $5,66 \%$ das amostras. LiUson (2003) também relatou a presença de Salmonella em peixes oriundos de pesqueiros e encontrou $7,8 \%$ das amostras positivas.

A presença dessa bactéria nos peixes pode ser atribuída à presença de mamíferos e aves no entorno dos viveiros.

Observa-se que não houve diferença estatística entre os números de micro-organismos pesquisados na água, pele e trato gastrintestinal o que reflete a relação direta entre a presença dos micro-organismos na água e nos dois locais analisados. No que se refere à musculatura, verifica-se que houve diferença significativa entre os números de micro-organismos na água ena musculatura, sendo que na musculatura os valores foram sempre menores. Este fato se relaciona com a proteção da musculatura à contaminação, $\mathrm{o}$ que não ocorre na pele e no trato gastrintestinal.

Uma análise, do ponto de vista sanitário, da relação direta entre a presença de micro-organismos na água, na pele e no trato gastrintestinal, coloca o pescado como veículo de contaminação cruzada. Sendo a pele e o trato gastrintestinal fontes de micro-organismos para sua própria musculatura e outros alimentos direta ou indiretamente. Assim, a qualidade da água deve ser monitorada e medidas de controle da sua contaminação aplicadas, no sentido de minimizar o risco de doenças transmitidas pelo consumo do peixe produzido nos pesque-pagues.

Diante do exposto, é evidente que a presença de enterobactérias nos diferentes órgãos dos peixes representa um risco potencialà saúde do consumidor. É certo também que estas bactérias são eliminadas pelo cozimento, porém, é importante frisar que a contaminação cruzada e o consumo de peixe cru podem ocorrer, equeconstituem fatores importantes na infecção e/ou intoxicação alimentar. Portanto, o monitoramento da qualidade da água é de suma importância, pois, além de garantir a produção de peixes com boa qualidade, garante também a preservação do ecossistema local.

\section{AGRADECIMENTOS}

Os autores agradecem à Fundação de Amparo à Pesquisa do Estado de São Paulo (FAPESP) pelo auxílio financeiro para realização da pesquisa e ao Conselho Nacional de Desenvolvimento Científico e Tecnológico (CNPq) pela bolsa de estudo concedida.

\section{REFERÊNCIAS}

AGÊNCIA NACIONAL DE VIGILÂNCIA SANITÁRIA. Brasil. Resolução RDC no 12 , de 02 de janeiro de 2001. Aprova o regulamento técnico sobre padrões microbiológicos para alimentos. Diário Oficial da União. Brasília, DF, 2001.

AL-HARBI, A.H. Faecal coliforms in pond water, sediments and hybrid tilapia Oreochromis niloticus X Oreochromis aureus in Saudi Arabia. Aquaculture Research, v.34, p.517-524, 2003.

AMERICAN PUBLIC HEALTH ASSOCIATION. APHA. Standard Methods for the Examination of Water and Wastewater. 20.ed. Washington DC: APHA, 1998. 
AMERICAN PUBLIC HEALTH ASSOCIATION. Compendium of methods for the microbiological examination of foods. 4.ed. Washington DC: APHA, 2001.

BOYD, C.E.; TANNER, M. Coliform organisms in waters of channel catfish ponds. Journal of the World Aquaculture Society, v.29, p.74-78, 1998.

CASTAGNOLLI, N. Status of aquaculture in Brazil. World Aquaculure, v.26, n.4, p.35-39, 1995.

CONSELHO NACIONAL DO MEIO AMBIENTE. (Brasil). Resolução n 357 de 17 de março de 2005. Dispõe sobre a classificação dos corpos de água e diretrizes ambientais para o seu enquadramento, bem como estabelece as condições e padrões de lançamento de efluentes, e dá outras providências. Diário Oficial da União, Brasília, DF, 2005.

COSTA, R.A.; VIEIRA, G.H.F.; SILVA, G.C.; PEIXOTO, J.R.O.; BRITO, M.V. Bactérias de interesse sanitário em sushi comercializado em Sobral - Ceará. Boletim TécnicoCientífico do CEPENE, v.15, n.1, p.15-19, 2007.

CUNHA, M.R.L.S.; PERESI, P.; CALSOLARI, R.A.O.; ARAÚJO JUNIOR, J.P. Detection of enterotoxins genes in coagulase-negative staphylococci isolated from foods. Brazilian Journal of Microbiology, v.37, p.70-74, 2006.

EKPERIGIN, H.E.; NAGAJARA, K.V. Microbial foodborne pathogens. Salmonella. The Veterinary Clinics of North America. Food Animal Practice, v.14, n.1, p.17-29, 1998.

EL-SHAFAI, S.A.; GIJZEN, H.J.; NASR, F.A;

EL-GOHARY, F.A. Microbial quality of tilapia reared in fecal-contaminated ponds. Environmental Research, v.95, p.231-238, 2004.

ESPOSTO, E.M.; SILVA, W.C.P.; REIS, C.M.F.; REIS, E.M.F.; RIBEIRO, R.V.; RODRIGUES, D.P.; LÁZARO, N.S. Enteropatógenos bacterianos em peixes criados em uma estação de reciclagem de nutrientes e no ecossistema relacionado. Pesquisa Veterinária Brasileira, v.27, n.4, p.144-148, 2007.

GATTI JUNIOR, P. Qualidade microbiológica e físico-química da água em pesque-pagues durante a estação seca. 2008. 44f. Trabalho de Conclusão de Curso (Graduação em Ciências Biológicas) - Faculdade de Ciências Agrárias e Veterinárias da Universidade Estadual Paulista, Jaboticabal, 2008.

GERMANO, P.M.L.; OLIVEIRA, J.C.F.; GERMANO, M. I. S. O pescado como causa de toxinfecções bacterianas. Higiene Alimentar, v.7, n.28, p.40-45, 1993.

GUZMÁN, M.C.; BISTONI, M.A.; TAMAGNINI, L.M.; GONZÁLEZ, R.D. Recovery of Escherichia coli in fresh water fish, Jenynsia multidentata and Bryconamericus iheringi. Water Research, v.38, p.2368-2374, 2004.

HUANG, S.L.; CHEN, W.C.; SHEI, M.C.; LIAO, I.C.; CHEN, S.N. Studies on Epizootiology and Pathogenicity of Staphylococcus epidermidis in Tilapia (Oreochromis spp.) cultured in Taiwan. Zoological Studies, v.38, n.2, p.178$188,1999$.

LANCELLOTTI, M. Estudo epidemiológico de Staphylococcus spp. em ambientes, água e portadores sadios e determinação da sensibilidade a antimicrobianos. 2006. 126f. Tese (Doutorado em Microbiologia Agropecuária) - Faculdade de Ciências Agrárias e Veterinárias da Universidade Estadual Paulista, Jaboticabal, 2006.

LINDER, C.E. Salmonella spp. em sistema intensivo de criação de peixes tropicais de água doce. 2002. 61f. Dissertação (Mestrado em Medicina Veterinária) - Faculdade de Medicina Veterinária e Zootecnia da Universidade Estadual Paulista, Botucatu, 2002.

LIRA, G.M; PEREIRA, W.D; ATHAYDE, A.H.; PINTO, K.P. Avaliação da qualidade de peixes comercializados na cidade de Maceió, AL. Higiene Alimentar, v.15, n.84, p.67-74, 2001.

LIUSON, E. Pesquisa de coliformes totais, fecais e Salmonella spp. em tilápias de pesqueiros da região metropolitana de São Paulo. 2003. 94f. Dissertação (Mestrado em Medicina Veterinária) - Faculdade de Medicina Veterinária e Zootecnia da Universidade de São Paulo, São Paulo, 2003.

MAC FADDIN, J.F. Biochemical tests for identification of medical bacteria. Baltimore: Williams \& Wilkins, 1976.312p.

MARTINS, F.O. Avaliação da qualidade higiênico-sanitária de preparações (sushi e sashimi) a base de pescado cru servidos em bufês na cidade de São Paulo. 2006. 142f. Dissertação (Mestrado em Saúde Pública) - Faculdade de Saúde Pública da Universidade de São Paulo, São Paulo, 2006.

MARTINS, C.V.B.; VAZ, S.K.; MINOZZO, M.G. Aspectos sanitários de pescados comercializados em "pesquepagues" de Toledo (PR). Higiene Alimentar, v.16, n.98, p.51-56, 2002.

NTENGWE, F.W; EDEMA, M.O. Physico-chemical and microbiological characteristics of water for fish production using small ponds. Physics and Chemistry of the Earth, v.33, p.701-707, 2008.

PÁDUA, H.B. Informações sobre os Coliformes totais/ fecais e alguns outros organismos indicadores, em sistemas aquáticos. 2003. 19p. Disponível em: <www.pescar.com.br/ helcias>. Acesso em: 15 dez. 2008.

PAL, D.; DASGUPTA, C. Microbial pollution in water and its effect on fish. Journal of Aquatic Animal Health, v.4, p.32-39, 1992.

RALL, V.L.M.; CARDOSO, K.F.G.; XAVIER, C. Enumeração de coliformes termotolerantes em pescados frescos e congelados. Publicações em Medicina Veterinária e Zootecnia, Londrina, v.2, n.39, p.1-8, 2008.

SAS INSTITUTE. SAS/STAT. Procedures guide for personal computers. Version 5 ed. SAS Institute: 1991. 
TAVARES, F.A.; LAPOLLI, F.R.; BATISTA, C.R.V.; MAIA, I.S.; JUNGLES, M.K. Reuso de efluentes domésticos na produção de tilápias - aspectos sanitários. In: CONGRESSO INTERAMERICANO AIDIS, 21., 2008, Santiago, Chile. Anais. Santiago: 2008. p.1-6.

VIEIRA, K.V.M; MAIA, D.C.C.; JANEBRO, D.I.; VIEIRA, R.H.S.F.; CEBALLOS, B.S.O. Influência das condições higiênico-sanitárias no processo de beneficiamento de tilápias (Oreocrhomis niloticus) em filé congelados. Higiene Alimentar, v.14, n.74, p.37-40, 2000.

YOUSSEF, H.; EL-TIMAWY, A.K.; AHMED, S. Role of aerobic intestinal pathogens of freshwater fish in transmission of humans diseases. Journal of Food Protection, v.55, n.9, p.739-740, 1992.

Recebido em 22/6/09

Aceito em 27/10/10 